Georgia State University

ScholarWorks @ Georgia State University

2012

\title{
Clocks and Trees: Isomorphic Dutch Auctions and Centipede Games
}

James C. Cox

Georgia State University, jccox@gsu.edu

Duncan James

Fordham University, dujames@fordham.edu

Follow this and additional works at: https://scholarworks.gsu.edu/econ_facpub

Part of the Economics Commons

\section{Recommended Citation}

Cox, James C., and Duncan James. 2012. "Clocks and Trees: Isomorphic Dutch Auctions and Centipede Games". Econometrica 80 (2). [Wiley, Econometric Society]: 883-903.

This Article is brought to you for free and open access by the Department of Economics at ScholarWorks @ Georgia State University. It has been accepted for inclusion in ECON Publications by an authorized administrator of ScholarWorks@ Georgia State University. For more information, please contact scholarworks@gsu.edu. 
CLOCKS AND TREES: ISOMORPHIC DUTCH AUCTIONS AND CENTIPEDE GAMES

Author(s): James C. Cox and Duncan James

Source: Econometrica, Vol. 80, No. 2 (March, 2012), pp. 883-903

Published by: Econometric Society

Stable URL: http://www.jstor.org/stable/41493837

Accessed: 15-01-2016 16:34 UTC

Your use of the JSTOR archive indicates your acceptance of the Terms \& Conditions of Use, available at http://www.jstor.org/page/ info/about/policies/terms.jsp

JSTOR is a not-for-profit service that helps scholars, researchers, and students discover, use, and build upon a wide range of content in a trusted digital archive. We use information technology and tools to increase productivity and facilitate new forms of scholarship. For more information about JSTOR, please contact support@jstor.org. 
Econometrica, Vol. 80, No. 2 (March, 2012), 883-903

\title{
CLOCKS AND TREES: ISOMORPHIC DUTCH AUCTIONS AND CENTIPEDE GAMES
}

\begin{abstract}
BY JAMES C. COX AND DUNCAN JAMES ${ }^{1}$
We report an experiment on effects of varying institutional format and dynamic structure of centipede games and Dutch auctions. Centipede games with a clock format unravel, as predicted by theory but not reported in previous literature on two-player tree-format centipede games. Dutch auctions with a tree format produce bids close to risk neutral Nash equilibrium bids, unlike previous literature on clock-format Dutch auctions. Our data provide a new, expanded set of stylized facts which may provide a foundation for unified modeling of play in a class of games that includes centipede games and Dutch auctions.
\end{abstract}

KEYWORDS: Experiment, game theory, centipede games, Dutch auctions, institutional format, dynamic structure.

\section{INTRODUCTION}

CENTIPEDE GAMES AND DUTCH AUCTIONS are two much studied games with a dynamic structure in which game theory fails empirically. Each of these games has a sequence of binary choices with two properties: (a) one of the choices ends the game immediately if chosen by a subject and (b) the payoff a subject earns by exercising that choice later in the game is greater than if he exercises the choice earlier in the game. In the centipede game, the prediction is that the subject with the first move will terminate the game immediately, whereas this unraveling prediction is typically not observed in experiments (McKelvey and Palfrey $(1992,1998)$, Zauner (1999)). In the Dutch auction, when the time frame for an auction period is comparable to that of a first-price sealed-bid auction, subjects allow the auction to continue longer than would be suggested by its isomorphism with the sealed-bid auction but shorter than would be consistent with risk neutral Nash equilibrium (Cox, Roberson, and Smith (1982), Turocy, Watson, and Battalio (2007)). In the two strands of the literature, different explanations for these empirical inconsistencies with theory have been proposed. By interchanging features of the two games, we hope to learn more about behavioral determinants of empirical regularities that can inform theory development for a class of games that contains centipede games and Dutch auctions. We focus on the games' institutional format (clock or tree) and dynamic structure (simultaneous or sequential move).

As in Selten's (1978) analysis of the chain store paradox, we look for game form characteristics that affect "... visualization of the possible consequences

\footnotetext{
${ }^{1}$ Three anonymous referees and a co-editor provided comments and suggestions that significantly improved the paper. Amnon Rapoport provided comments on an earlier version. Financial support was provided by the National Science Foundation (Grants IIS-0630805 and SES-0849590). Krawee (Kevin) Ackaramongkolrotn, Darryl McLeod, Erick Rengifo, and Todd Swarthout rendered vital aid (repeatedly).
} 
of different choices...." The tree format provides advance presentation of all possible payoffs in a centipede game or Dutch auction, whereas the clock format only presents some present payoff information. We ask whether the additional information provided by the tree format helps subjects to find strategies that increase their payoffs beyond what they attain with the clock format. For the Dutch auction, higher earnings with a tree format than with a clock format correspond to lower bids that are closer to Nash equilibrium bids. For the centipede game, higher earnings with a tree format than with a clock format correspond to later take nodes which are further away from the theoretical prediction of unraveling to a take at the first opportunity. We do observe these effects, and explain how they challenge existing theory for both Dutch auctions and centipede games.

\section{RELATED LITERATURE}

\subsection{Dutch Auctions}

In his book on the history of auctions, Cassady (1967) discussed types of auctions that have been used for long historical periods. He defines "Dutch auction" as follows (Cassady (1967, p. 67)):

In this auction the offer price starts at an amount believed to be higher than any bidder is willing to pay and is lowered by an auctioneer or a clock device until one of the bidders accepts the last offer. The first and only bid is the sales price in the Dutch auction.

One implication of Cassady's definition is that any bidder who stops the auction near the beginning is likely to lose money. This is a defining characteristic of Dutch auction that we do not change.

Vickrey (1961) first explained that the Dutch auction is theoretically isomorphic to the first-price sealed-bid auction in the independent private values (IPV) information environment. Cox, Roberson, and Smith (1982), Turocy, Watson, and Battalio (2007), and Katok and Kwasnica (2008) tested this isomorphism by comparing revenue (and bids) in the Dutch and first-price auctions. Different results for this comparison were found with different Dutch auction clock speeds. In contrast, all of these papers report average Dutch auction bids greater than expected risk neutral Nash equilibrium (RNNE) bids for all Dutch clock speeds. For example, data and statistics reported by Katok and Kwasnica (2008, pp. 348, 350) imply that average Dutch auction bids were significantly greater than the expected RNNE bid (of 50) for all of their (1, 10 , and 30 second) clock speeds. Dutch auction bids greater than RNNE bids have been attributed to risk aversion (Cox, Roberson, and Smith (1982)) and impatience (Katok and Kwasnica (2008)). Our paper takes the approach of modifying the characteristics of auctions so as to better understand their properties. Our modified Dutch auctions differ from previous literature in that we focus on variation in institutional format and dynamic structure rather than variation in clock speed. Our experiment compares two dynamic institutions in 
which (clock or tree node) decision opportunity speeds are carefully chosen to be the same. We used the middle (10-second) speed used by Katok and Kwasnica, but choice of any conventional clock (and tree node) speed should not affect our results.

\subsection{Centipede Games}

The centipede game presents a tension between what economists might suppose to be an agent's wish to obtain a higher payoff for himself by waiting to take and a desire to avoid getting zero (or a low) payoff by waiting so long that the other player takes first. ${ }^{2}$ This tension within an agent, and the potential for each agent to develop beliefs about this tension (and other possible motivations) in other agents makes the centipede game a potential test bed for hypotheses on a range of subjects.

For instance, does the predicted unraveling outcome (taking at the first node) occur in experiments? McKelvey and Palfrey (1992) found that generally it did not. What are the implications of failure to play according to the theoretical prediction? McKelvey and Palfrey (1992) discussed whether subjects' altruism could explain the empirical failure of the unraveling prediction. McKelvey and Palfrey (1998) examined the explanatory possibilities of a particular error-in-choice model, quantal response equilibrium. Zauner (1999) examined whether "independent perturbed payoffs" could explain the data (and estimated the magnitude of noise in perceived payoffs needed to do so).

Experiments that vary characteristics of games can be used to assess their significance as determinants of behavior. Rapoport, Stein, Parco, and Nicholas (2003) found that more players and increased payoffs appeared to increase the incidence of unraveling in centipede games. Further work by Murphy, Rapoport, and Parco (2006) investigated the effect of moving from $n=3$ to $n=7$ players, and of changing the proportions according to which total payoffs at a node were allocated across the one "winner" and the $n-1$ "losers," finding a strong effect from increasing $n$ and a milder effect from the change in allocation of payoffs. Our paper also takes the approach of varying characteristics of games so as to better understand their properties. Our modified centipede games differ from Rapoport et al. (2003) and Murphy, Rapoport, and Parco (2006) in that we focus on variation in institutional format and dynamic structure rather than variations in number of players or absolute and relative size of payoffs. Our centipede games differ from McKelvey and Palfrey (1992) in our use of private values, linear growth in total payoffs, and zero payoffs for not ending the game.

\footnotetext{
${ }^{2}$ The choice of final node payoffs in our centipede games is determined by the pairing with Dutch auctions. If the Dutch auction price clock ticks to zero (or to a positive seller reserve price) without any bidder choosing to buy, then all bidders receive zero surplus. Hence the natural pairing of centipede games with Dutch auctions is to set all players' payoffs to zero at the final node in a centipede game, as in Aumann's (1995) game.
} 


\subsection{Where Our Paper Fits in the Literature}

To identify the role of institutional format, it is necessary that an exact correspondence in message spaces across isomorphic games be maintained. This design principle, already put forth for the comparison of the Dutch auction and the first-price sealed-bid auction by Cox, Roberson, and Smith (1982), is similarly applicable to IPV centipede games presented in different institutional formats (i.e., clock versus tree). Thus we compare tree format to clock format while holding constant dynamic structure (sequential or simultaneous moves), payoff increment per discrete unit of time, and number of players. We use a 10 -second tick speed in the clock format that is the same as the speed with which the computer advances the active decision node in the tree format if a player has not stopped the game by a taking choice. We also compare simultaneous move structure to sequential (or alternating) move structure while holding constant institutional format, payoff increment per discrete unit of time, and number of players.

Our paper contributes to the literature by experimenting with the effects of changes in institutional format and dynamic structure. If such changes produce significant changes in behavior, this would suggest that parameters from models such as, say, quantal response equilibrium (McKelvey and Palfrey (1998)) or independent perturbed payoffs (Zauner (1999)) would have to vary across different representations of the same game, thus leading one to reflect on the generality of those models. We look at both Dutch auctions and centipede games in the same study because this allows us to ascertain if any dependence of bids or takes on format or dynamic structure generalizes across games. Additionally, it should be noted that complete unraveling of the centipede game (however operationalized) with only two players and few repetitions would be a new type of empirical result. Also, Dutch auction bids consistent with RNNE bids would be a new type of result.

\section{EXPERIMENT DESIGN}

\subsection{Sequential-Move Dutch and Centipede Clock Games}

The sequential-bid Dutch auction with clock format differs from the traditional Dutch auction in one way: bidders alternate price clock ticks at which they are allowed to bid. At a given clock reading, only one bidder has the right to bid at that clock price; the other bidder(s) have to wait until the clock ticks to their turn before they have a chance to bid. In the two bidder, $\$ 1.00$ price decrement case in our design, the price on the clock starts at 11 and one bidder can bid at clock prices $10,8,6,4$, or 2 , while the other bidder can bid at clock prices $9,7,5,3$, or 1 . The bidders' private values for the auctioned item are independently drawn from the uniform distribution on $[1.01,1.02, \ldots, 10.99,11.00]$, which supports an interior Bayesian-Nash equilibrium (see Section 4.1). This version of the Dutch auction is presented to bidders as shown in Figure 1 (for the first price tick). 


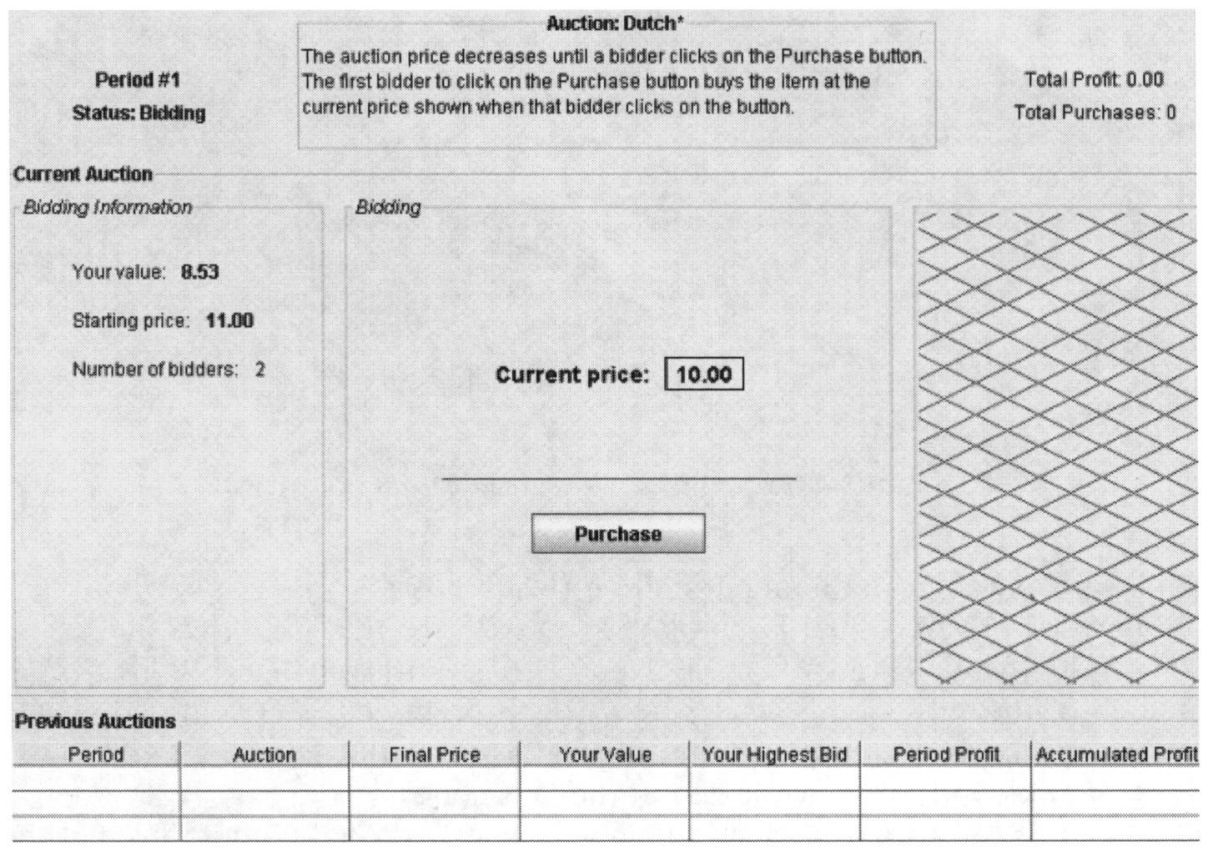

FIGURE 1.-Clock-format sequential-bid Dutch auction.

The sequential-take IPV centipede game with clock format maintains the alternating decision opportunities that characterize the traditional game; in the two-player, $\$ 1.00$ price tick decrement game we utilize in our design, one player can take at price clock readings of $10,8,6,4$, or 2 , while the other player can take at price clock readings of $9,7,5,3$, or 1 . However, instead of having common information about opponents' exact payoffs (as in the traditional centipede game), agents know that players' private values are independently drawn from the uniform distribution on $[11.01,11.02, \ldots, 20.99,21.00]$. This is sufficient to support an unraveling prediction (as shown below in Section 4.2). This version of the centipede game is presented to subjects in clock format exactly as the Dutch auction shown in Figure 2 except a player's private value (seen in the upper left of the display) would be higher (specifically, it would lie between 11.01 and 21.00).

\subsection{Sequential-Move Centipede and Dutch Tree Games}

We use an IPV information environment for our version of the sequentialtake centipede game in tree format (just as in the clock format). Each player has an initial value drawn from a uniform distribution on $[0.01,0.02, \ldots, 9.99$, $10.00]$, to which an amount $n$ is added at each subsequent decision node $n=$ $1,2, \ldots, 10$, which supports an unraveling prediction (as shown in Section 4.2). 


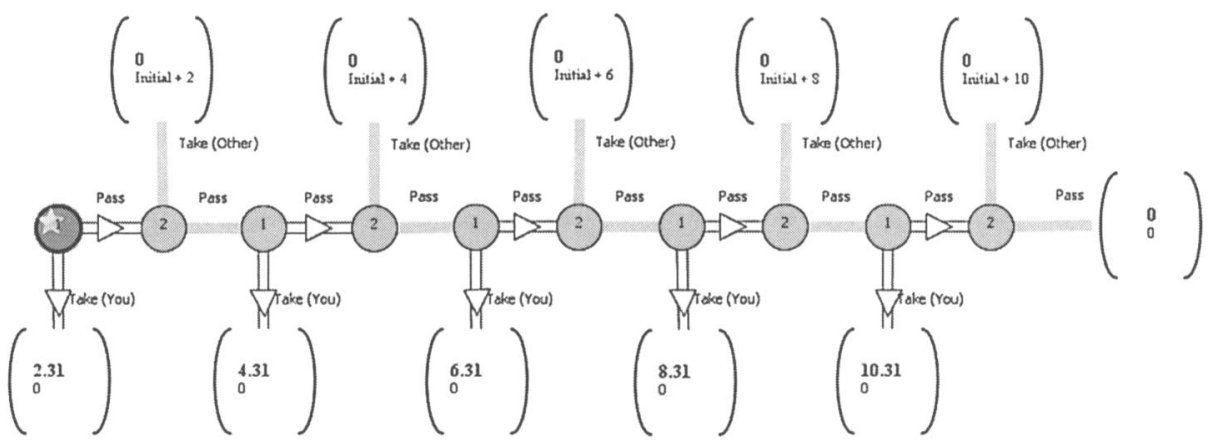

FIGURE 2.-Tree-format sequential-move centipede game.

A player's payoff from taking at node $n$ (when possible) is $v_{j}+n$, where $v_{j}$ is the player's private value. Each player can only see that the other player has some initial value (drawn from a given distribution) to which is added $\$ 2.00$ at each of the subsequent other player's decision nodes. The centipede game in tree format is presented to the subjects as shown in Figure 2 (with "live" decision node indicated by the star at the first node).

When it is her turn, a subject can choose whether to take (and thus end the game) at the current live decision node. If the subject does not choose her take option during the 10-second opportunity, the computer advances the live node indicator to the next node in the game (which belongs to the other player). A player cannot speed up the game by making an active "pass" decision. The length of the 10 -second live node speed for the tree format corresponds exactly to the 10 -second clock speed for the clock format.

The tree format sequential Dutch auction represents the auction with an extensive form game tree rather than a price clock. It appears exactly as the tree format IPV centipede game pictured in Figure 2, except that each bidder has an initial value drawn from the uniform distribution on $[-9.99,-9.98, \ldots,-0.01,0.00]$.

\subsection{Simultaneous-Move Dutch and Centipede Clock Games}

The simultaneous-bid Dutch auction in clock format is the standard form of that auction. The simultaneous-take IPV centipede game in clock format functions and looks like the format shown in Figure 1 except that the "purchase" button is live for both agents at every 10 -second tick of the clock.

\subsection{Simultaneous-Move Centipede and Dutch Tree Games}

The simultaneous-bid Dutch auction in tree format differs from the standard Dutch auction only in that a tree format is used rather than a clock format. The simultaneous-take IPV centipede game with tree format, shown in Figure 3, 


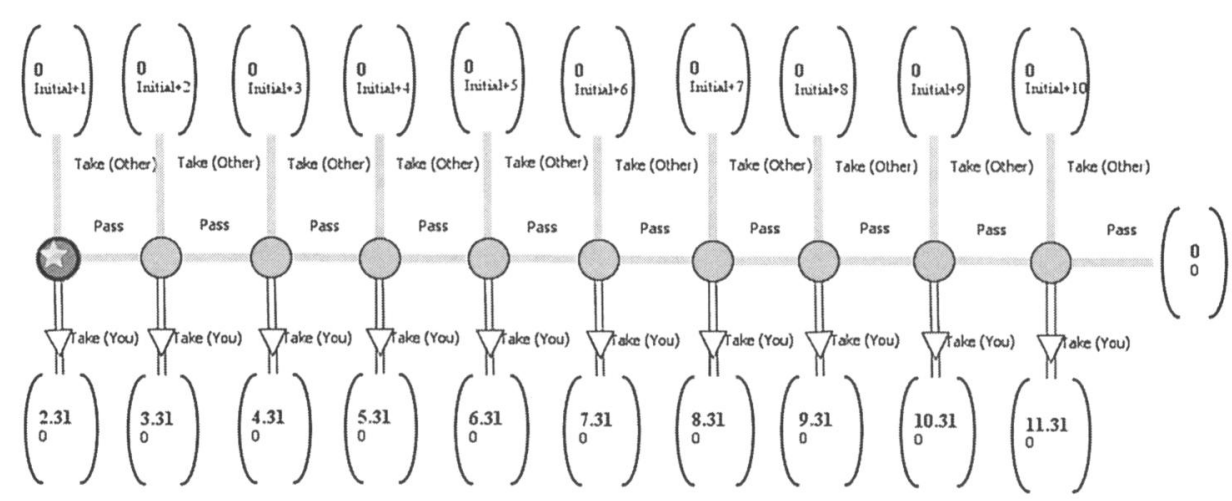

FIGURE 3.-Simultaneous-move tree-format games.

allows each player to take at any node which has been reached; players' payoffs are still private information (as denoted by "Initial + 1," etc.).

\subsection{Additional Experimental Design Features}

In addition to design choices intended primarily to hold constant dynamic structure across institutional formats, we also made certain design choices to minimize the differences in parameterization across treatments. We did this so as to minimize potential sources of confounds. First, we used an 11 tick clock or 11 node tree with 10 -second decision opportunity in every treatment. Second, all games utilized an independent private values information environment; again, this removes a potential confounding difference for interpreting results across games. Third, all games utilized a uniform distribution with a support width of $\$ 10.00$ as the source of independent private values; again, this standardization removes an impediment to comparisons across games. Fourth, subjects were randomly matched in pairs, each round. Finally, it should be pointed out that when all of these design choices were implemented, it left a design where all it took to switch between the sequential Dutch auction and the IPV centipede game was a $\$ 10.00$ shift in the location (low value, high value, or midrange) of the $\$ 10.00$-wide support of the uniform distribution used to generate independent private values. The eight treatments in the $2 \times 2 \times 2$ design of the experiment are shown in Figure $4 .^{3}$ Additional data programs, figures,

\footnotetext{
${ }^{3}$ While Treatment 8 is exactly the traditional Dutch auction, in arriving at the design summarized in Figure 4 there are necessarily several parameterization differences introduced between the centipede game addressed in McKelvey and Palfrey (1992) and the closest thing to it in Figure 4, which is Treatment 1 . Those parameterization differences include geometric versus linear growth of the sum of payoffs, nonzero payoff versus zero payoff for the player who does not stop first, and terminal payoffs of zero if the final node is reached. Also, it is worth repeating that the information environment used is IPV, so this necessarily both deletes and adds informa-
} 


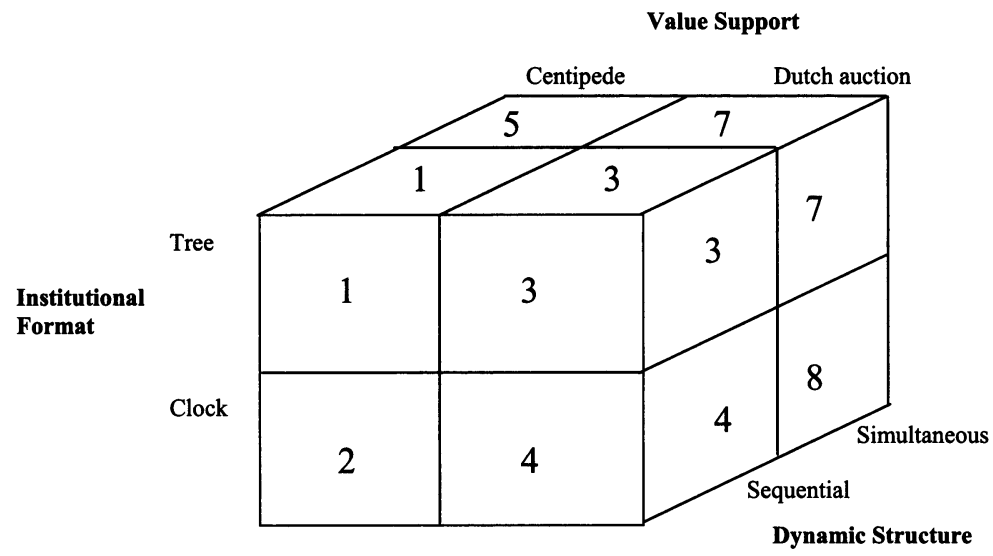

FIGURE 4.-Experiment design (design variables on axes; treatment numbers in cells).

and instructions to experimental subjects are supplied in the Supplementary Material (Cox and James (2012)).

The experiment design thus allows one to detect inconsistencies with theoretical predictions for a given (Dutch auction or centipede) game in a given format, differences between results generated using the clock and the tree formats for a given game, and differences in deviations from theoretical predictions between the sequential-move and simultaneous-move structures of a game.

If there is a difference in the distributions of bids for Treatment 3 (T3) and Treatment 4 (T4), then the isomorphism across institutional formats of the sequential-bid Dutch auction fails; if there is a difference in the distributions of takes between Treatment 1 (T1) and Treatment 2 (T2), then the isomorphism across institutional formats of the sequential-take IPV centipede game fails; and so on throughout the experimental design cube. In general, we would like to determine whether either the clock format or the tree format leads to earlier or later bids or takes across games, such that this aspect of the results would appear to be driven by institutional format rather than characteristics of the games captured by existing theory. ${ }^{4}$

tion relative to the common information case; that is, by presenting the opponent's payoff (were they to take) as "Initial value +1.00 ," "Initial Value +2.00 ," and so on, a component of the opponent's payoff is suppressed (deleting information), but the change in the opponent's payoff over time is made more explicit by disaggregation (adding, or at least emphasizing, information). That there are (unavoidable) differences in parameterization between the game studied here and that in McKelvey and Palfrey (1992) should be kept in mind; further exploration of alternative parameterizations is a promising avenue for future empirical work.

${ }^{4}$ Additional details of our design are as follows. Each experiment session took approximately 2 hours. In each session, we ran subjects through three treatments with 10 rounds in each treatment. After reading instructions for any one of the treatments, subjects participated in three practice rounds with hypothetical payoffs and were given opportunities to ask questions to pro- 


\section{THEORETICAL PREDICTIONS}

For the two games in each pair to be isomorphic, they need to have the same dynamic structure. We accomplished this by allowing subjects 10 seconds at a given price clock reading or decision node in the tree to click with a mouse to bid or to take. If, at the end of 10 seconds, the subject has not bid or taken, the game advances to the next price clock reading or decision node in the tree; the subject could not actively select "not to bid" or "not to take." The change in payoff from one decision opportunity to the next one was set equal to $\$ 1.00$ in all games. All games had a default setting of zero payoffs for both players in the event of "no bid" in the auction or "no take" in the centipede game. We did this because we needed the same end-of-game payoffs across games to preserve isomorphism and because the default of "no transaction" is natural for Dutch auctions. ${ }^{5}$

\subsection{Predictions for the Sequential-Bid Dutch Auction}

In our sequential Dutch auction with clock format, the odd-price bidder can bid at clock prices of $9,7,5,3$, and 1 . The even-price bidder can bid at clock prices of $10,8,6,4$, and 2 . The two bidders' values for the auctioned item are independently drawn from the uniform distribution on $[1.01,1.02, \ldots, 10.99,11.00]$. Values and bids are discrete, hence the bid functions are step functions. The risk neutral Bayesian-Nash equilibrium bid functions for odd-price bidder and even-price bidder are as follows. Let $b_{s}^{j}\left[l_{s}^{j}, h_{s}^{j}\right]$ denote that values in the range $\left[l_{s}^{j}, h_{s}^{j}\right]$ support an equilibrium bid of $b_{s}^{j}$ by the odd-price bidder $(j=o)$ or the even-price bidder $(j=e)$. No values support bids of 9 or 7 by the odd-price bidder or bids of 10 or 8 by the even-price bidder.

mote understanding of the treatment format. No subject participated in more than one session. The paired treatment sequences of the form A-B-A and B-A-B provide controls for learning and other possible sequencing effects. The first, second, and third sets of 10 rounds are referred to, respectively, as parts 1,2 , and 3 . We used the following sequences of treatments in parts 1,2 , and 3: T1-T2-T1, T2-T1-T2, T2-T3-T2, T3-T2-T3, T3-T4-T3, T4-T3-T4, T1-T4-T1, and T4-T1-T4; T5-T6-T5, T6-T5-T6, T6-T7-T6, T7-T6-T7, T7-T8-T7, T8-T7-T8, T5-T8-T5, and T8-T5-T8. For example, the first listed treatment sequence consisted of 10 rounds of $\mathrm{T} 1$ in part 1 , followed by 10 rounds of $\mathrm{T} 2$ in part 2 , followed by 10 rounds of $\mathrm{T} 1$ in part 3 . We used an integer clock price decrement and node payment increment in all treatments to facilitate quick recognition of payoff information by subjects. We used a 2 to 1 experimental dollar to U.S. dollar exchange rate; this was needed to keep payments affordable if we were going to keep using a $\$ 10.00$-wide uniform distribution for value draws. We did not just shrink all numbers by $50 \%$ to keep payoffs affordable because we wanted integer payoff changes between decision opportunities, as noted above.

${ }^{5}$ Payoffs which deviated from the McKelvey and Palfrey design were used by Fey, McKelvey, and Palfrey (1996) and Huck and Jehiel (2004). The latter set the payoff to the loser at 0.10 pounds regardless of who wins or when (we use 0.00 dollars regardless of who or when); also, they started each subject at a different initial payoff. The latter design is related to ours as follows: if one made the accumulation in payoffs linear and made the initial payoffs private information, it would in effect be what is utilized here. 
The other parts of the equilibrium bid functions are

odd-price bidder: $5[7.25,11.00], 3[3.59,7.24], 1[1.01,3.58]$;

even-price bidder: $\quad 6[9.32,11.00], 4[5.41,9.31], 2[2.00,5.40]$.

The bid functions were first solved numerically; straightforward calculation verifies that they satisfy the best reply property. The tree format is strategically equivalent.

\subsection{Predictions for the Sequential-Take IPV Centipede Game}

The theoretical prediction for the tree format centipede game with sequential-take opportunities and independent private values is unraveling to a take at the first opportunity. Let the two players have any two values $v_{1}$ and $v_{2}$ drawn from the support $[0.01,0.02, \ldots, 9.99,10.00]$ for the uniform distribution of values. This creates a situation where the first mover could earn $v_{1}+t$ at take nodes $t=1,3, \ldots, 9$, while the second mover could earn $v_{2}+\tau$ at take nodes $\tau=2,4, \ldots, 10$. The player who does not take earns zero at all nodes. If neither player has taken by the time the second player's final take node has timed out (after 10 seconds), both players earn zero. This suggests that if the second player's final take node were to be reached, the second player would take and would earn $v_{2}+10$, while the first player would receive zero. A rational first player would anticipate this and take at the preceding node, but a rational second player would anticipate this and take at the preceding node, and so on. The theoretical prediction for the IPV centipede game is unraveling to a take at the first node. The clock format is strategically equivalent.

\subsection{Predictions for the Simultaneous-Bid Dutch Auction}

The risk neutral bid function for the simultaneous-bid Dutch auction with clock format and values drawn from a uniform distribution on $[1.01,1.02, \ldots$, $10.99,11.00$ ] and with each player able to bid at $10,9,8,7,6,5,4,3,2$, or 1 are as follows. Let $b_{s}\left[l_{s}, h_{s}\right]$ denote that values in the range $\left[l_{s}, h_{s}\right]$ support a bid at price $b_{s}$ on the Dutch price clock. No values support bids of $10,9,8,7$, or 6 . The other parts of the of the Bayesian-Nash equilibrium bid function are

both bidders: $5[7.67,11.00], 4[6.46,7.66], 3[4.16,6.45]$,

$$
2[2.47,4.15], 1[1.01,2.46] \text {. }
$$

The bid function was solved numerically with equations embodying conditions 1-4 in Chwe (1989). Chwe's conditions characterize the pure strategy Nash equilibrium bid function in a first-price auction with a discrete bid space. Our 
numerical solution satisfies the inequalities in Chwe's Proposition 1. The isomorphism between the first-price and Dutch auctions is invoked to apply that solution here. ${ }^{6}$ The tree format is strategically equivalent.

\subsection{Predictions for the Simultaneous-Take IPV Centipede Game}

Let the two players have any two values $v_{1}$ and $v_{2}$ drawn from the support $[0.01,0.02, \ldots, 9.99,10.00]$ for the uniform distribution. This creates a situation where player $a$ would earn $v_{a}+t$ if she takes at node $t=1,2, \ldots, 10$, while player $b$ would earn $v_{b}+t$ if he takes at node $t$. The player who does not take earns zero. If both players try to take at the same node, the probability that either succeeds in taking is $1 / 2$. If neither player has taken by the time the final take node has timed out, both players earn zero. Therefore, if node 10 were to be reached, both players would want to take at that node and the probability that either would succeed would be $1 / 2$. A rational player would anticipate this and consider the expected payoff from taking at node 9 . If player $k$ does not try to take at round 9 , then player $j$ prefers to take because she would succeed with probability 1 and receive payoff $v_{j}+9$, which is greater than the expected payoff from waiting until node 10 , which is $1 / 2 \times\left(v_{j}+10\right)$. If player $k$ does try to take at round 9 , then player $j$ prefers to take because she would succeed with probability $1 / 2$ and receive expected payoff $1 / 2 \times\left(v_{j}+9\right)$, which is greater than the zero amount that would be received from not trying to take at round 9. Therefore, each player prefers to take rather than pass at round 9. Similar reasoning shows that each player prefers to take rather than pass at round 8 , and so on back to round 1 . The clock format is strategically equivalent.

\section{RESULTS}

Experiment sessions were run in the laboratory of the Experimental Economics Center (ExCEN) at Georgia State University. 544 subjects took part in the experiment (and 43 others participated in a pilot or were recruited as alternates). 414 subjects participated in at least one 10-round sequence of Dutch auctions; 362 participated in at least one 10-round sequence of centipede games; 232 participated in simultaneous-move treatments; and 312 participated in sequential-move treatments.

\subsection{Method of Data Analysis}

The statistical results are generated by panel data regressions. The dependent variable is deviation from the applicable theoretical prediction. The in-

\footnotetext{
${ }^{6}$ Chwe (1989) demonstrated uniqueness of the pure strategy Bayesian-Nash equilibrium bid function for the discrete simultaneous-bid auction. Similar arguments to his can be used to establish uniqueness of the pair of (odd-price and even-price) pure strategy bid functions for the discrete sequential-bid auction as well.
} 
TABLE I

DATA ANALYSIS FOR DUTCH AUCTIONS ${ }^{\mathrm{a}}$

\begin{tabular}{|c|c|c|c|c|c|c|}
\hline \multirow[b]{2}{*}{ Variable } & \multicolumn{2}{|c|}{$\begin{array}{l}\text { Sequencing-Based } \\
\text { Treatment } \\
\text { Dummies Only }\end{array}$} & \multicolumn{2}{|c|}{ Subject Fixed Effects } & \multicolumn{2}{|c|}{$\begin{array}{l}\text { Random Effects (and } \\
\text { Structurally Based } \\
\text { Treatment Dummies) }\end{array}$} \\
\hline & Coeff. & $p$-Value & Coeff. & $p$-Value & Coeff. & $p$-Value \\
\hline Constant/Tree-Cent.-Tree & 0.0777 & 0.403 & 0.6913 & 0.000 & 0.0703 & 0.544 \\
\hline Clock & 0.5373 & 0.000 & 0.5855 & 0.000 & 0.5760 & 0.000 \\
\hline Time $(t)$ & 0.0136 & 0.005 & 0.0117 & 0.007 & 0.0123 & 0.005 \\
\hline Simult. & 0.3617 & 0.000 & - & - & 0.3385 & 0.000 \\
\hline Clock-Tree-Clock & 0.4653 & 0.000 & - & - & 0.4489 & 0.002 \\
\hline Tree-Clock-Tree & 0.1854 & 0.099 & - & - & 0.2165 & 0.118 \\
\hline Clock-Cent.-Clock & 0.1312 & 0.332 & - & - & 0.1141 & 0.478 \\
\hline Cent.-Clock-Cent. & 2.0428 & 0.000 & - & - & 2.3261 & 0.000 \\
\hline Cent.-Tree-Cent. & 1.4114 & 0.000 & - & - & 1.6361 & 0.000 \\
\hline Clock-Tree-Clock $* t$ & -0.0270 & 0.000 & -0.0254 & 0.000 & -0.0260 & 0.000 \\
\hline Tree-Clock-Tree $* t$ & -0.0257 & 0.000 & -0.0262 & 0.000 & -0.0263 & 0.000 \\
\hline Clock-Cent.-Clock $* t$ & -0.0056 & 0.400 & -0.0061 & 0.313 & -0.0061 & 0.312 \\
\hline Cent.-Clock-Cent. $* t$ & -0.1292 & 0.000 & -0.1580 & 0.000 & -0.1471 & 0.000 \\
\hline Cent.-Tree-Cent. $* t$ & -0.0863 & 0.000 & -0.1090 & 0.000 & -0.0993 & 0.000 \\
\hline$R^{2}$ & \multicolumn{2}{|c|}{0.0967} & \multicolumn{2}{|c|}{0.3761} & \multicolumn{2}{|c|}{0.0738} \\
\hline
\end{tabular}

${ }^{\mathrm{a}} N=4475$ in all cases ( 5 missing observations due to network congestion within the experiment).

dependent variables are binary treatment variables (clock or tree, simultaneous or sequential), time, treatment sequence intercept dummies (thus the constant in each regression is actually the average deviation from equilibrium for that treatment sequence held back from receiving its own intercept dummy), and treatment-sequence "slope" dummies (thus the estimate for time coefficient is actually for the holdout treatment sequence). Fitted values for a given round and treatment sequence are obtainable from estimated coefficients (and the round number) according to fitted value $=$ constant + institutional format + dynamic structure + sequence intercept + (time coef. + sequence slope coef.) $*$ round number.

\subsection{Dutch Auction Results}

Table I shows results from an econometric analysis of Dutch auction data. The dependent variable is actual bid less RNNE bid (given in Section 4). The data show a dramatic difference in behavior across isomorphic versions of the sequential Dutch auction employing different institutional formats and dynamic structures. Various forms of econometric specification lead to the same conclusions: deviations from predicted bids are greater in the clock format than in the tree format; deviations are greater in the simultaneous structure than in the sequential structure; where bidding changes over time, it moves 


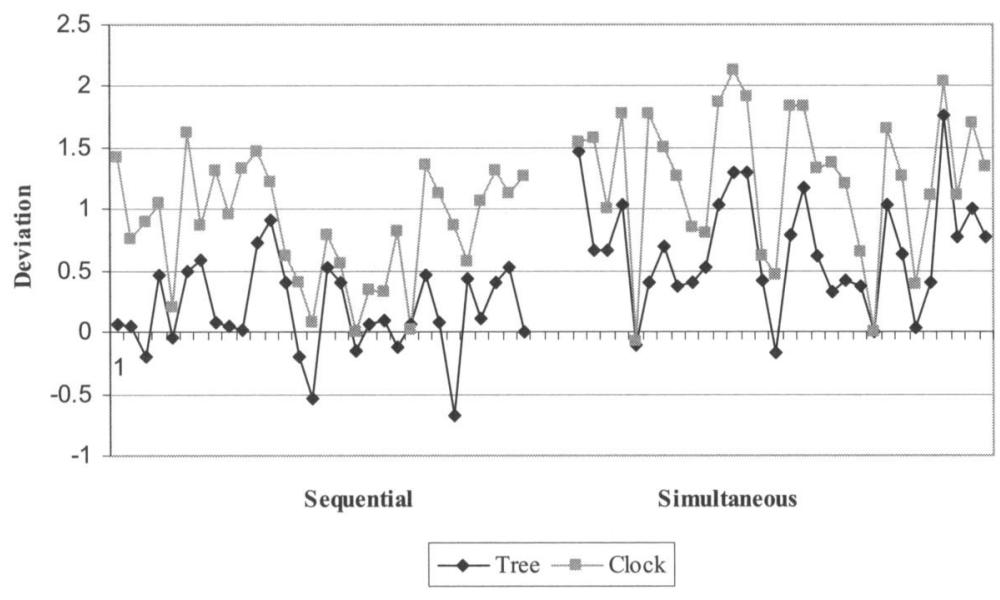

FIGURE 5.-Bid deviations in Dutch auctions.

almost exclusively in the direction of the predicted bid functions. The structural dummies reflect the sequencing detailed in footnote 4; the data from similar sequences (e.g., clock-tree-clock) across sequential and simultaneous versions are addressed by the same structural dummy for reasons of simplicity and space; regressions employing different structural dummies across otherwise similar sequential and simultaneous treatment sequences yield similar results. The interaction terms (e.g., Clock-Tree-Clock $* t$ ), when summed with the time coefficient, capture change in behavior over time for a given treatment sequencing. Bold type in a table denotes treatment data used in estimation reported in that table while nonbold type denotes an intervening treatment with data used in estimation reported in the other table.

The various estimation procedures return almost identical estimates. The one exception would initially appears to be subject fixed effects, but even that is really telling us the same thing. The seeming difference is due to the inability to estimate subject fixed effects in the presence of sequence dummies and the "simultaneous or sequential" treatment dummy (because the treatments used different subjects). Since these variables must be dropped to run that estimation, their impact shows up through the fixed effects.

Figure 5 shows a time series plot of the average deviation from the theoretical prediction in each round. It shows how the results differ across treatments and where they lie relative to the theoretical prediction in each round. The bid deviations from RNNE are not significantly different from zero for some sessions and most rounds in the sequential tree format (indeed 952 out of the 1425 winning bids are at or below the risk neutral prediction). This level of elimination of overbidding the RNNE is unprecedented for Dutch auctions (with any clock speed). It should be noted that-due to space and visual clarity constraints-rounds 11-20 in these figures mix subject groups who had already 
TABLE II

DATA ANALYSIS FOR CENTIPEDE GAMES ${ }^{\mathrm{a}}$

\begin{tabular}{|c|c|c|c|c|c|c|}
\hline \multirow[b]{2}{*}{ Variable } & \multicolumn{2}{|c|}{$\begin{array}{l}\text { Sequencing-Based } \\
\text { Treatment } \\
\text { Dummies Only }\end{array}$} & \multicolumn{2}{|c|}{ Subject Fixed Effects } & \multicolumn{2}{|c|}{$\begin{array}{l}\text { Random Effects (and } \\
\text { Structurally Based } \\
\text { Treatment Dummies) }\end{array}$} \\
\hline & Coeff. & $p$-Value & Coeff. & $p$-Value & Coeff. & $p$-Value \\
\hline Constant/Clock-D.A.-Clock & 0.757 & 0.000 & 1.162 & 0.000 & 0.772 & 0.000 \\
\hline Clock & -0.396 & 0.000 & -0.413 & 0.000 & -0.408 & 0.000 \\
\hline Time $(t)$ & -0.008 & 0.002 & -0.009 & 0.000 & -0.009 & 0.001 \\
\hline Simult. & -0.213 & 0.000 & - & - & -0.204 & 0.000 \\
\hline Clock-Tree-Clock & -0.170 & 0.015 & - & - & -0.182 & 0.023 \\
\hline Tree-Clock-Tree & 0.891 & 0.000 & - & - & 0.918 & 0.000 \\
\hline Tree-D.A.-Tree & 0.670 & 0.000 & - & - & 0.703 & 0.000 \\
\hline D.A.-Clock-D.A. & 0.444 & 0.056 & - & - & 0.434 & 0.057 \\
\hline D.A.-Tree-D.A. & 1.870 & 0.000 & - & - & 1.859 & 0.000 \\
\hline Clock-Tree-Clock $* t$ & 0.001 & 0.616 & 0.002 & 0.513 & 0.002 & 0.541 \\
\hline Tree-Clock-Tree $* t$ & -0.048 & 0.000 & -0.049 & 0.000 & -0.049 & 0.000 \\
\hline Tree-D.A.-Tree $* t$ & -0.039 & 0.000 & -0.033 & 0.000 & -0.034 & 0.000 \\
\hline D.A.-Clock-D.A. $* t$ & -0.027 & 0.065 & -0.025 & -0.088 & -0.026 & 0.060 \\
\hline D.A.-Tree-D.A. $* t$ & -0.105 & 0.000 & -0.104 & 0.000 & -0.104 & 0.000 \\
\hline$R^{2}$ & \multicolumn{2}{|c|}{0.298} & \multicolumn{2}{|c|}{0.439} & \multicolumn{2}{|c|}{0.278} \\
\hline
\end{tabular}

${ }^{\mathrm{a}} N=3680$ in all cases.

been in the Dutch auction in rounds 1-10 with subject groups who had spent rounds 1-10 in the centipede game; the regressions control for this difference in sequencing; notably, tree sessions preceded by centipede sessions bid unusually high initially, but drop rapidly toward the prediction.

\subsection{Centipede Results}

Table II shows results from an econometric analysis of centipede game data. The dependent variable is actual take node less predicted take node (that is, node 1). The analysis uses an approach to treatment sequencing dummies similar to that in Section 5.2, and is as follows. As with the Dutch auction, we find that takes/bids are earlier using the clock format and earlier using simultaneous structure, and that, over time, behavior moves in the direction of equilibrium (the latter in a far more pronounced manner than in the Dutch auction). Figure 6 plots the time series of the average deviation in take from the theoretical prediction for each institutional format. Note at the outset that moving to an IPV environment does not in itself eliminate the failure to unravel typical when using the tree format and common information (for $n=2$ ). Clearly, knowing the other player's exact payoff information is not necessary for generating failure to unravel; this can be seen in the early round results for the tree-format sequential centipede game shown in Figure 6. 


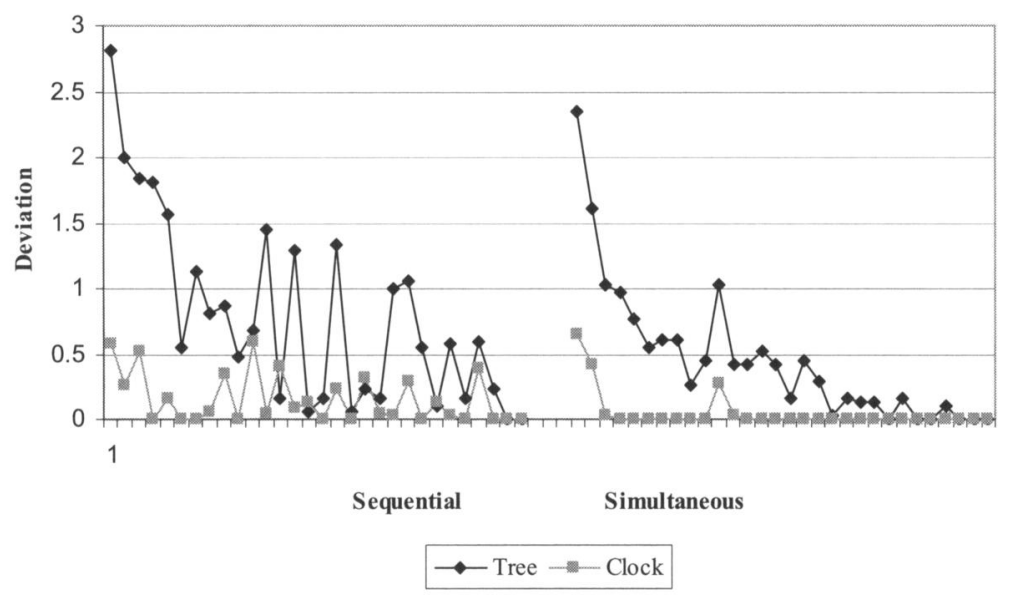

FIGURE 6.-Take deviations in centipede games.

The clock-format centipede games show very distinctive results. Indeed, from round 4 onward the clock-format simultaneous-take centipede game exhibits perfect unraveling in 25 of 27 rounds by every pair of subjects across all experiment sessions. This prevalence of unraveling is unprecedented for twoplayer centipede games.

To this point we have oriented graphs and presented data in a manner suggested by traditional treatment of Dutch auctions and centipede games. We now present a graph, Figure 7, of a representative round of data (the first round results from the sequential structure games) where all auctions and games are ordered by a common axis: ticks elapsed at the time play was terminated. The graph is suggestive of the notion that behavior across these heretofore sepa-

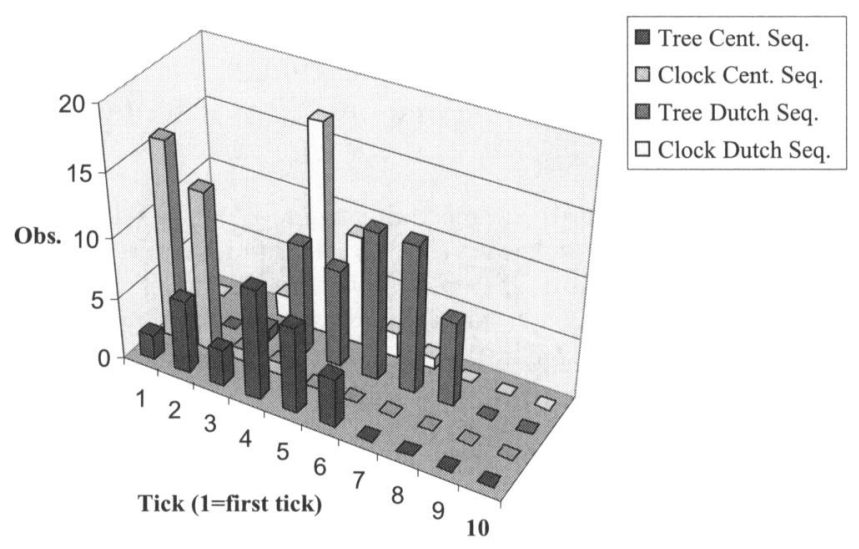

FIGURE 7.-First round play in sequential structure games viewed on a common axis. 
rately analyzed games might actually be understood on a common basis: clocks support earlier exits and trees support later exits. We explore this notion in the next section.

\section{IMPLICATIONS FOR MODELING PLAY IN THE GAMES}

We get some striking results. Winning bids are consistently higher and successful take nodes consistently earlier with the clock format than with the tree format for four games. The centipede game unravels much earlier with the clock format than the tree format. In the Dutch auction, we can obtain results close to the risk neutral Nash equilibrium prediction when we use the tree format but not when we use the clock format. Ironically, we get data that more closely resemble theoretical predictions for both centipede games and Dutch auctions when we use the format that is not traditionally associated with that market or game. This implies that previously existing "stylized facts" about behavior in these games-and theory based on those stylized facts-are called into question because they ignore the effect of institutional format on behavior.

The tree format appears to provide information that subjects use to increase their payoffs (relative to clock format) in both Dutch auctions and centipede games. With Dutch auctions, the higher payoffs from trees come from lower bids that are closer to the RNNE prediction. With centipede games, the higher payoffs from trees come from later takes that are further from the unraveling prediction.

The results from these experiments provide a new set of stylized facts, or empirical regularities, to guide modeling. First, models of behavior should allow for an interaction between aspects of institutional design-institutional format being of particular interest-and subjects' formulation of strategy. The results across different institutional formats for the same game are inconsistent with modeling approaches that are insensitive to this. Second, models of behavior should allow for at least the possibility of learning; at a minimum, the results from the tree-format IPV centipede games are inconsistent with static models. ${ }^{7}$

\footnotetext{
${ }^{7}$ While a counterargument might be advanced that the more modest change over time in the Dutch auction results rules out models that allow for learning, we do not believe that this is the way to proceed. Most importantly, the environment in the Dutch auction experiments, as is typical in (IPV) auction experiments, redraws values for each subject, each round; given the value support associated with the Dutch auction, this leads to the predicted bids for each subject and the predicted winning bids across subjects changing from round to round. In contrast, even though the IPV form of the centipede game redraws values similarly, the equilibrium in the IPV centipede never moves; it is always a take at the first node. Thus the Dutch auction experiments provide a more difficult learning environment in which subjects would have to learn to hit a moving target. In this light, failure of, say, the simultaneous tree-format Dutch auction to converge to equilibrium across time to the degree shown in either tree-format IPV centipede game might be understandable.
} 
As we think again about how to proceed in future modeling, it is worth revisiting the notion that how subjects perceive and play games and how economists model and solve games are not necessarily the same. As a profession we know that there is (at least) a layer of modeling that we must be missing; we have not advanced so far as to be able to expect all of the results we see from experimental work (as shown by the results in this paper and much literature). The "missing layer" of subject perception was identified by Selten (1978) in the context of the chain store paradox. Specifically, he nominates "... the visualization of the possible consequences of different choices..." as a potential key step in strategy selection and, thus, a possible influence on the ultimate outcome of the game. This visualization-or construction of a mental model of the game-is essential to any subject's subsequent behavior in an economic institution. How else are they even to begin to play?

The informational differences between the institutional formats employed in the experiment reported here, and the possible implications for subjects' apprehension of game structure and formulation of strategy are stark. The tree format visually displays at all times to the subject everything they need to know about every aspect of an institution: message space, allocation rules, cost rules, and adjustment process rules, in their entirety, throughout the length of the game. (Alternatively, the same point can be made in terms of strategy spaces, payoff functions, and so on.) Representations of all of these could be extracted and named by an economist/game theorist examining the game tree; an untrained subject might not be able to name any of them, but would not need to do so to be informed by them. The clock format provides none of these, except at whatever happens to be the present tick. This would make no difference to our economist/game theorist (as they would be able to formulate strategy ex ante from a description of the game), but might prove crippling to an untrained subject, who would then not only have to try to derive an optimal approach to play over the course of the game, but also first have to conceptualize abstractly what features of the game are important and how they should be characterized or represented.

One possible illustration of the importance of this contrast might be seen in the difference in dispersion of bids/takes across the tree and clock formats in early rounds. In Figure 7, for both the centipede game and the Dutch auction, the clock format produces data plots where almost all observations fall into just two bins - a tight, peaked empirical density-while the tree format produces much more spread out plots, with four or five bins receiving substantial shares of the observations. Keeping in mind that Figure 7 represents the first round of play, before any learning from experience can occur, these plots are as close as we can get to observing play based solely on subjects' homegrown apprehension of game structure. What the plots suggest is that subjects in the clock format seem myopic: they simply are not trying out much of the usable strategy space. (Note also that this is in addition to the already noted fact that in the clock format the subjects stop closer to the beginning of the temporally 
ordered strategy space.) Given standard theoretical predictions, the data so produced would map to overbidding in the Dutch auction, but to near equilibrium play in the centipede game; in each case, however, we might be seeing the consequences of myopic subjects where such myopia is largely a function of the institutional format employed. ${ }^{8}$ Conversely, the first round tree-format data, which are suggestive of less myopia and more willingness to experiment with strategy selection-possibly due to a greater appreciation of the extent of the strategy space-are neither uniformly on-target nor off target from the standpoint of theoretical predictions. The Dutch auction data are centered on the equilibrium prediction, but the centipede data are (as typically) too far into the interior of the tree (though the subjects are at and above the theoretical profit predictions, respectively).

In later rounds, learning from past play potentially starts to play a role. The drawing power of the traditional equilibria does show, in the data analysis reported in Tables I and II, in the shrinking over time of deviations from equilibrium that is implied by negative values for the "sum of time coefficient plus treatment-sequence time interaction coefficient" (4 of 6 such sums are negative for the Dutch auction; 6 of 6 such sums are negative for the centipede game). If an equilibrium conflicts with the subjects' default desire to play further down the tree than the equilibrium predicts, then as the experiment continues, the properties of the equilibrium can eventually win out; in the treeformat centipede game, the subjects cannot maintain the initial late takes, instead gradually unraveling to the equilibrium at the first node. Conversely, if an equilibrium does not conflict with bids/takes well into the interior of the strategy space, the subjects might happily roost there indefinitely-provided they can find it in the first place; subjects facing the sequential tree Dutch auction seem to be able to do something like this. In contrast, the paucity of information in the clock format encourages subjects to take early regardless and counter to their own interest. The subjects facing the clock format "achieve" the dubious distinction of quickly attaining equilibrium in the centipede game in part because they start out almost at it; the subjects in the clock format miss the interior equilibrium in the simultaneous Dutch auction by a huge margin, even though they would be better off at it instead, but denied explicit forwardlooking information (by the clock format), they are unable to find it. ${ }^{9}$

\footnotetext{
${ }^{8}$ Naïve, myopic behavior with a clock would lead to rapid convergence to predicted dominant strategy bidding in IPV single unit English auctions. In this case, all a bidder needs to notice to conform to theory is that possible earnings are maximized by remaining in the auction while known item value exceeds clock price at the present tick and exiting as soon as this fails to be true. Behavior consistent with this was observed by Harstad (2000) in English clock auction experiment results. In contrast, there is widespread and persistent bidding above value in the (theoretically isomorphic) second-price sealed-bid auction Harstad (2000) in which bidders have to "figure it out" that bids equal to value are the dominant strategy.

${ }^{9}$ Simultaneous versus sequential structure plays a part in the results too. Specifically, when simultaneous structure is present, subjects' bids (and deviations above predictions) are higher. This
} 
The challenge now is to find a model that is capable of encompassing all of this. There are some leads with respect to how this might be approached. For example, given that we would now desire a model of choice that incorporates gradations in the apprehension of strategic alternatives and the possibility of evolution of strategy in response to past observations, a modified form of experience-weighted attraction (EWA) (Camerer and Ho (1999)) might be a possible starting point. For instance, what if EWA could be augmented with (a) construction of a mapping between institutional features (among them institutional format) and the $\delta$ parameter (governing visualization of payoffs to strategies other than those previously chosen by the agent), and (b) construction of a mapping between institutional features and initial attractions (the initial conditions for the raw material for the probability mass accorded a particular strategy)? We already know, from the simulation results of James and Reagle (2009) for EWA agents in the first-price sealed-bid auction, that $\delta \approx 0$ and $\varphi \approx 1$ yields persistent overbidding in the first-price sealed-bid auction (over the 500-round horizon used), while with $\delta=1$ and $\varphi=1$, EWA agents more rapidly converge to expected value maximizing behavior. ${ }^{10}$ Given that $\delta=0$ corresponds to myopia about payoffs to alternative strategies, while $\delta=1$ corresponds to being fully informed about them, it is tempting to try to map the tree format to a high value of $\delta$ and map the clock format to a low value of $\delta$; certainly the clear differences in informational content between the two institutional formats suggest that $\delta$ should differ across institutional formats and do so for reasons other than convenience in explaining the particular results in this paper. A similar exercise to seed the initial attractions (to various strategies) might be justified along the same lines and would close the EWA model in this application. This is not our only suggestion, however. Analogy-based expectation equilibrium (Jehiel (2005)) might be a better candidate to explain at least some aspects of our results; in particular, the earlier takes/higher bids seen with simultaneous rather than sequential structure seem to be a natural outcome for agents using that reasoning system, with coarse information partitions over past play. In our design, recall of past play would be endogenous and

is supported as a separate marginal effect in our statistical analysis. Thus when both simultaneous structure and clock format are present, the two different effects work in the same direction and (over)bidding is extremely high. When neither is present, the risk neutral prediction is attained in most rounds. When one is present and the other is absent, we get intermediate results, but our design and our statistical analysis allow for the parsing of this. On an intuitive level, what may be going on in the simultaneous version is that the possibility that another bidder might win the game while one is looking at the screen, considering alternatives, at least partially counteracts the ability of the tree format to promote later bids/takes.

${ }^{10}$ In EWA, $\varphi$ controls the subjects' recall of past round information $(1=$ perfect recall, $0=$ no memory). A role for $\varphi$ is not addressed in our conjectures, as our design did not present information on previous rounds. The only way something like $\varphi$ could have had an impact would have been if different formats are better or worse at promoting the subjects' own formation of memory; this is not to say this could not have happened and it is something worth a look in future research. 
dependent on subjects' memories of their own play. Exploration of the impact of exogenously varied provision of information on past play in these games is an interesting topic for future research, and one that could help further establish the suitability of candidate explanatory models.

We believe that the results in this paper provide new insights into properties of alternative institutional formats that should stimulate new theory development for a class of games that includes centipede games and Dutch auctions. Previously, anomalous results in markets or games have been addressed by recourse to either of two types of explanation: newer, more complicated models of subjects' choices or an invocation of the broad notion that "institutions matter." In contrast, we wish to put forth the notion that the interaction between specific aspects of subjects' information processing abilities and particular features of alternative institutional formats might be driving empirical results. Specifically, varying the manner in which a market or game is displayed (its format) might directly interact with subjects' abilities of visualization/apprehension of strategic possibilities. (Similarly, varying the provision of information on past outcomes might directly interact with subjects' abilities of recall.) This represents an advance toward understanding how and why institutions matter, as opposed merely to pointing out that they do. In addition, it is worth emphasizing that prior to the results in this paper, researchers had no reason not to take for granted that there was only one way to format and structure a Dutch auction or centipede game, and that said "unique" approach was in no way misleading about possible behavior in the game. The experiment reported here generates new stylized facts-that for the first time include significant observations of both unraveling in two person centipede games and risk neutral bidding in Dutch auctions-which may provide a foundation for unified modeling of play in a class of games that includes centipede games and Dutch auctions.

\section{REFERENCES}

AumanN, R. J. (1995): "Backward Induction and Common Knowledge of Rationality," Games and Economic Behavior, 8, 6-19. [885]

CAMERER, C. F., AND T.-H. Ho (1999): "Experience-Weighted Attraction Learning in NormalForm Games," Econometrica, 67, 827-874. [901]

CASSADY, R. (1967): Auctions and Auctioneering. Los Angeles: University of California Press. [884]

CHWE, M. S.-Y. (1989): “The Discrete Bid First Auction,” Economics Letters, 31, 303-306. [892, 893]

CoX, J. C., AND D. JAMES (2012): "Supplement to 'Clocks and Trees: Isomorphic Dutch Auctions and Centipede Games'," Econometrica Supplemental Material, 80, http:// www.econometricsociety.org/ecta/Supmat/9589_instructions to experimental subjects.pdf; http://www.econometricsociety.org/ecta/Supmat/9589_data and programs.zip; http://www. econometricsociety.org/ecta/Supmat/9589_figures.pdf. [890]

COX, J. C., B. ROBERSON, AND V. L. SMITH (1982): "Theory and Behavior of Single Object Auctions," Research in Experimental Economics, Vol. 2, ed. by V. L. Smith. Greenwich: JAI Press. $[883,884,886]$ 
Fey, M., R. D. MCKelvey, AND T. R. PAlfRey (1996): "An Experimental Study of ConstantSum Centipede Games," International Journal of Game Theory, 25, 269-287. [891]

HARSTAD, R. M. (2000): "Dominant Strategy Adoption and Bidders' Experience With Pricing Rules," Experimental Economics, 3, 261-280. [900]

HUCK, S., AND P. JEHIEL (2004), "Public Statistics and Private Experience: Varying Feedback Information in a Take or Pass Game," Working Paper, UCLA Department of Economics. Available at http://ideas.repec. org/p/cla/levrem/122247000000000733.html. [891]

JAMES, D., AND D. REAGLE (2009), "Experience Weighted Attraction in the First Price Auction and Becker DeGroot Marschak," in 18th World IMACS Congress and MODSIM09, ed. by R. S. Anderssen, R. D. Braddock, and L. T. H. Newham. Australia: Modelling and Simulation Society of Australia and New Zealand Inc., 1437-1441. Available at http://www.mssanz.org.au/modsim09/D8/james.pdf. [901]

JeHIEL, P. (2005): “Analogy-Based Expectation Equilibrium," Journal of Economic Theory, 123, 81-104. [901]

KATOK, E., AND A. M. KWASNICA (2008): "Time Is Money: The Effect of Clock Speed on Seller's Revenue in Dutch Auctions," Experimental Economics, 11, 344-357. [884]

MCKelvey, R., AND T. R. PAlfrey (1992): "An Experimental Study of the Centipede Game," Econometrica, 60, 803-836. [883,885,889,890]

_ (1998): "Quantal Response Equilibria for Extensive Form Games," Experimental Economics, $1,9-41$. [883,885,886]

MURPHY, R. O., A. RAPOPORT, AND J. E. PARCO (2006), "Breakdown of Cooperation in Iterative Real-Time Trust Dilemmas," Experimental Economics, 9, 147-166. [885]

RAPOPORT, A., W. E. STEIN, J. E. PARCO, AND T. E. NichOlAS (2003): "Equilibrium Play and Adaptive Learning in a Three Person Centipede Game," Games and Economic Behavior, 43, 239-265. [885]

SElten, R. (1978): “The Chain Store Paradox," Theory and Decision, 9, 127-159. [883,899]

Turocy, T. L., E. WATSON, AND R. C. BatTalio (2007): "Framing the First-Price Auction," Experimental Economics, 10, 37-51. [883,884]

VICKREY, W. (1961): “Counterspeculation, Auctions, and Competitive Sealed Tenders," Journal of Finance, 16, 8-37. [884]

ZAUNER, K. G. (1999): "A Payoff Uncertainty Explanation of Results in Experimental Centipede Games," Games and Economic Behavior, 26, 157-185. [883,885,886]

Experimental Economics Center (ExCEN) and Dept. of Economics, Andrew Young School of Policy Studies, Georgia State University, P.O. Box 3992, Atlanta, GA 30302-3992, U.S.A.; jccox@gsu.edu

\section{and}

Dept. of Economics, Fordham University, Dealy Hall, Bronx, NY 10458, U.S.A.; dujames@fordham.edu.

Manuscript received October, 2010; final revision received July, 2011. 